\section{Observation of Ultracentrifugal Sedimentation by the Toepler Schlieren Method}

Fon the observations of concentration distribution in an ultracentrifuge cell during the process of sedimentation, methods depending on light absorption or refractive index have been used ${ }^{1,2}$. According to the latter procedure, as used in the sedimentation velocity measurements, a scale is photographed through the cell; from the measurements of the displacement of the scale divisions in the distorted image on the photographic plate, the concentration gradient in different parts of the cell is calculated. The resulting gradient diagrams show the number of components present, and their sedimentation velocities and concentrations can be accurately calculated.

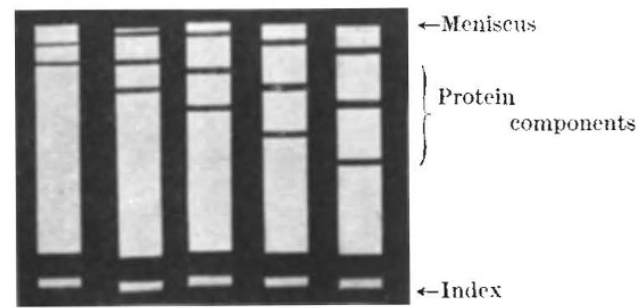

Fig. 1.

Sedimentation Pictures of hamocyanin From Limulus polyphemus at $p \mathrm{H} 6 \cdot 8.5$ MIN. BETWEEN exposures. Centrifugal FIELD: 120,000 TIMES graVity. Cell thickness: 12 m. The BLACK BANDS REPRESENT THE THREE COMPONENTS SEDIMENTING MOST RAPIDLY.

The well-known Toepler Schlieren method, also depending upon the deviation of a beam of light in a concentration gradient, has been used for many similar purposes ${ }^{3}$. Recently, one of us (A. T.) applied this procedure to electrophoresis measurements with quite satisfactory results ${ }^{4}$. The method has now been tried in observations of sedimentation velocities ;



Fig. 2.

SEDIMENTATION PICTURE OF A PATHOLOGICAL SERUM (8 PARTS OF SERUM DILUTED WITH 3 PARTS OF A CONCENTRATED PHOSPHATE BUFFER). $p H$ 6.8. TOTAL SALT CONCENTRATION : 0.25 MOLAR. $10 \mathrm{~min}$. BETWEeN EXPosures. Centrifugal FIELd : 350,000 times gravity. Cell thickness : 3 ma. Besides THE THREE COMPONENTS SEEN IN THE FIGURE, A FOURTH SLOW SEDIMENTING ONE APPEARED AT THE MENISCUS IN IAATER EXPOSURES. (NORMAL SERUM UNDER THE SAME CONDITIONS SHOWS ONLY TWO COMPONENTS.)

some examples are given in Figs. 1 and 2. The following optical arrangement is used (Fig. 3): A lens placed as closely as possible behind the centrifuge cell projects an image of a horizontal slit through the cell on to the camera objective. In front of this is a vertically movable screen, having a horizontal edge with which any part of a deviated image of the slit may be cut off. When the screen is properly arranged, any gradients occurring in the cell will give rise to corresponding black bands visible to the eye in the image of the cell and recorded on the plate in the camera, as shown in Figs. 1 and 2 . A tungsten ribbon lamp with a condenser lens is used for illumina. tion of the slit.

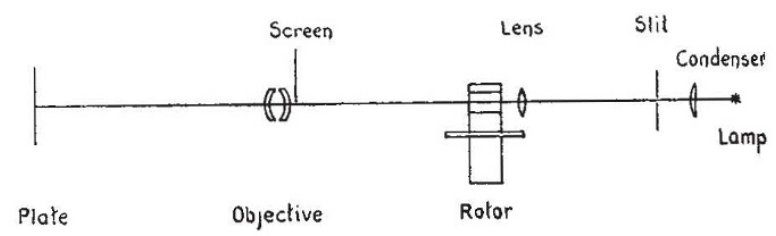

Fig. 3.

The method offers the advantage of rapid and convenient observation of components in mixtures and their sedimentation velocities. It also gives a rough idea of the relative amounts of the differently sedimenting substances. It may be modified also to give a more accurate determination of concentra. tion $^{5}$, but for this purpose it does not seem to offer any advantage over the very accurate scale method previously mentioned.

Arne Tiserius.

Kai O. Pedersen.

INGA-Britta ERIKSSON-QUENSEL.

Institute of Physical Chemistry,

Uppsala, Sweden.

Feb. 11.

1 Svedberg, The, Z. physik. Chem., 121, 65 (1926).

${ }^{2}$ Lamm, Ole, Z. physik. Chem., A, 138, 313 (1928) ; Z. physik. Chem., A, 143, 177 (1929); Nature, 132, 820 (1933).

s Sce for example: F. Kohlrausch, "Lehrbuch der praktischen Physik", and reference 5 below

'Tiselius, A., Trans. Faraday Soc. (in the Press).

'Schardin, H., "Das Toeplersche Schlierenverfahren" (VDI-Verlag, Berlin, 1934)

\section{Liquid Crystalline Preparations of Cucumber Viruses 3 and 4}

IN a previous note ${ }^{1}$, we showed that liquid crystalline substances infective at high dilutions could be isolated from solanaceous plants infected with three different strains of tobacco mosaic virus. We have been unable to transmit these strains to cucumber plants, and other workers have found cucumber to be immune to tobacco mosaic virus. From cucumber plants infected with cucumber viruses 3 and $4^{2}$, we have now isolated nucleoproteins with a similar chemical composition and similar in many of their properties to those obtained from solanaceous plants infected with tobacco mosaic virus; they are, how. ever, rather less stable and more difficult to isolate.

Of the methods of isolation yet tried, the following has proved most effective : expressed infective cucumber sap is coagulated by heating to $70^{\circ} \mathrm{C}$., centrifuged and the supernatant fluid one quarter saturated with ammonium sulphate. A precipitate 